\title{
Problems of Introduction and Evolution of Electronic Signature in Georgia and Topical Issues Regarding Their Solution
}

\section{Genadi Iashvili ${ }^{1}$, Tinatin Iashvili ${ }^{2}$, Tamta Glonti $^{3}$ \& Besik Sherazadishvili ${ }^{4}$}

${ }^{1}$ Doctor of Technical Sciences. Professor. Head of the Department of Public Administration and Electronic Business. Faculty of Business Technology, Georgian Technical University. (Tbilisi, Georgia).

${ }^{2}$ Academic Doctor of Social Sciences, Professor of the Department of Public Administration and Electronic Business, Faculty of Business Technology, Georgian Technical University. (Tbilisi, Georgia).

${ }^{3}$ Academic Doctor of Public Administration. Assistant Professor of the Department of Public Administration and Electronic Business, Faculty of Business Technology, Georgian Technical University. (Tbilisi, Georgia).

${ }^{4}$ Academic Doctor of Public Administration. Assot. Professor of the Department of Public Administration and Electronic Business, Faculty of Business Technology, Georgian Technical University. (Tbilisi, Georgia).

DOI - http://doi.org/10.37502/IJSMR.2022.5112

\section{Abstract}

In the modern world, electronic services and their digital solutions are an easy way for citizens, the public and private sectors to solve existing issues.

Nowadays, various types of services are provided in a digital form in order to increase management efficiency and make systems more flexible, accessible and simple (ensuring growing success of any organization).

Especially against the background of the coronavirus pandemic, electronic communication and the rapid development of digital technology have become extremely important. The emergence of global information systems, in particular the Internet, has completely changed not only any person's daily routine but also spiritual, intellectual life and business activity. The benefits and importance of the Internet have become apparent to the world, moved into a virtual space due to force majeure circumstances which affected daily life - personal and business relationships.

Digital democracy, as the peak of the quality of democracy, increases citizen involvement in making decisions on national issues, thus promoting more control and dynamism. It is noteworthy that, to some extent, the establishment of digital democracy and electronic governance is a result of information technology.

At present, success of any organization in any sector is essentially dependent on the management based on electronic components.

The paper considers the issue of electronic signature, namely it is noted that using technologies, the public sector seeks to make public goods available to citizens easily and 
quickly. It is also emphasized, that studying the situation in the public and private sectors in this aspect is very important in order to analyze the factual reality in Georgia.

This scientific article analyzes the problems relating to the introduction and evolution of electronic signature in Georgia and topical issues regarding their solution.

Keywords: electronic governance, electronic signature, introduction, public sector, private sector, electronic services.

\section{Introduction}

Hypothesis: the introduction of electronic systems in public administration in the form of electronic governance makes the work of bureaucracy more flexible and at the same time reduces bureaucratic barriers for the population; the introduction of information technology can significantly improve service quality and the ways of access to services for citizens.

The purpose of the paper is to identify the issues, relating to the risks of electronic governance at present, analyze the issue of electronic signatures and present mechanisms to improve personal data protection in general.

The novelty of the paper: our scientific article analyzed the reality regarding electronic governance and, in particular, the risks of introduction of an electronic signature in Georgia. We analyzed the "Technology Acceptance Model' 'among the tools for measuring society's ability to adapt to innovations. In our article we also presented the system Signify.ge, developed in recent years in Georgia, in which the relevant data are created for each signed document.

\section{The objectives of the paper:}

1. To study the reality of electronic governance (in particular, an electronic signature, personal data) in Georgia at the present stage;

2. To analyze current reforms and changes in the system of electronic governance and electronic signature at the legislative level;

3. To identify the problems in the sphere of personal data protection in Georgia and propose ways to improve the existing situation, taking into account the experience of foreign countries;

4. To identify the problems / challenges revealed as a result of the study and find ways to solve them.

The subject of the study is the challenges revealed as a result of current reforms in the sphere of electronic governance and electronic signature.

The object of the study is the strategies for personal data protection, the risks of electronic signature and the legal framework regulating the electronic signature system.

Theoretical-methodological basis: the theoretical-methodological basis of the study is Georgian and foreign science books and published articles on the risks of electronic governance and electronic signature. The methodology, used in the scientific study, is based on three main directions: online services, information technology infrastructure and human capital in the country. Finally, after analyzing all three aspects, the development index of electronic governance in a particular country is determined. 
The role of the Public Service Development Agency in the development of electronic governance in Georgia and in the process of introducing electronic signature:

LEPL Public Service Development Agency is a legal entity under public law operating within the governance of the Ministry of Justice of Georgia. It was established on the basis of LEPL Civil Registry Agency in July 2012. The function of Public Service Development Agency is to support the development of its services as well as public services, in general; to introduce innovative services in the public sector; to maintain and constantly improve the registry of citizens and issue related documents.

The Agency has the functions of Civil Registry: functioning the system of registering citizens of Georgia, registering civil acts, issuing identity documents, managing procedures relating to migration, managing procedures relating to citizens, legalizing and certifying documents by apostille, etc.

The Agency also has a relatively new function which implies assisting public agencies: facilitating development and improvement of public services, creating new services, generating ideas, diagnosing processes and identifying needs, preparing recommendations for optimal solutions of problems, preparing and implementing plans for optimizing processes.

Due to its functions, the Public Service Development Agency is involved in several important projects. One of them, may say the most important ongoing project, is "Introduction of E-governance in Local Governments" which has been implemented with the financial support of the European Union. The project aims at building capacity of local governments through improving governance in local government entities, providing quality services to local population and developing local infrastructure.

In order to support the introduction of electronic governance in local governments the Municipal Management System (MMS) is used. The main purpose of the system is to register citizens' applications electronically and automate processes to optimize the decisionmaking process.

One of the most important components of the project is to provide an access to safe and effective municipal electronic services on the 'single window" principle via citizen's portal - my.gov.ge.

Any natural or legal person, registered on this portal, can remotely register an application in any municipalities involved in the MMS. Applications submitted in this way are automatically sent to the relevant municipal services which manage electronic workflow through the MMS. The project is divided into several phases (2011-2014 (Phase I); 20142016 (Phase II); 2016-2017 (Phase III); 2017-2020 (Phase IV)) and has an ongoing status up to now. [1]

According to the purposes of the project, partners / participants involving in the project are: target municipalities, National Agency of Public Registry, Financial- Analytical Service of the Ministry of Finance, Data Exchange Agency, Training Center of Justice of Georgia, Company "3 Line", Ministry of Regional Development and Infrastructure of Georgia and Ministry of Economy and Sustainable Development.

The main tools of electronic governance are digital technologies and communication systems, by which websites are created. Information about tenders, contests, vacancies, news, laws, regulations, and other public information is posted on the websites. Electronic 
governance enables the public sector to decrease costs, reduce human and material resources, overcome distance, and speed up workflow with business.

The Ministry of Economy and Sustainable Development of Georgia includes the Department of Communications, Information and Modern Technologies, which, within its competence, performs the following main function: the main directions of state policy and participating in their implementation in such fields as electronic communications, information technologies, mail and scientific technological innovations.

There are several levels of implementing electronic governance. At the first level, there is one-way communication - the website of a state agency informs citizens about news, structure, officials, budget or planned events. As a result of a relatively high level of interactive electronic communication, two-way communication is established between the citizen and the state. Online consultation is available on the website of the state agency. In addition, as a result of registration, it is possible to provide various types of electronic services to citizens. At the highest or most inclusive level of electronic governance, citizens themselves participate in the decision-making process. Citizens are actively involved in the discussion relating to the topics which are important for them. There are 7 different ways to perform this task, for example: creating electronic petitions, posting opinions on the site, by polling or participating in a forum. The relationship between the state, business and citizens, cooperation, trends in relationship, management concept, conditions and types of service provision are transformed in the state management by means of information technologies. Information and communication technology (ICT) is used in the state management according to the concept of electronic governance which enables to manage the state effectively and efficiently. The fundamental goals of electronic governance are: [2]

- performing management functions quickly, effectively and creatively;

- developing electronic governance;

- simplifying and improving the aspects of business and state management;

- facilitating interaction between citizens, state organizations and selected organizations;

- establishing electronic federalism; developing electronic democracy;

- managing information;

While shaping national electronic environment, the principles of development of tasks and programs in the field of electronic governance are:

- implementing national strategy and policy within the framework of development of information and communication technology;

- developing telecommunications infrastructure;

- establishing a normative legal basis;

- developing human resources;

- Stimulating the development of electronic governance.

It is noteworthy that electronic governance does not only change the type of communication, it also requires a change of actors, namely public servants and citizens. Both parties need appropriate skills to use electronic systems in order to provide or receive public services. [3] 
The introduction of technology in the public sector has changed the type of bureaucracy- from traditional bureaucracy to the electronic one. The development of electronic governance has led to the growing popularity of electronic services in the bureaucratic apparatus. The main drawback of the traditional bureaucracy was the lack of efficiency and rationality in performing its functions. It was characterized by managerial unity, predictable routine and processes. The stability of the system was considered as a more important factor than changes in the personal structure, which meant that the structure functioned regardless of who held the position.

The modernization of the public administration process has transformed the traditional system into New Public Management. Together with the establishment of New Public Management principles, a new idea emerged that information and communication technologies could become a mechanism that would increase the effectiveness of the bureaucratic apparatus. (Hughes, 2001). [4]

Information and communication technologies, especially the Internet are considered as a mechanism for reinventing bureaucracy. All of this leads to the transformation of the traditional bureaucratic model, focused on standardization, organizational division, and operational cost-efficiency, into a bureaucracy which emphasizes the principles of network management, external cooperation, and customer orientation in the electronic governance paradigm. [5]

Some researchers argue that despite the high financial costs, there is no significant evidence that the benefits of electronic governance are adequate to financial resources spent on it (Castelnovo, 2010), while some researchers suppose that the emergence of the term "Electronic government paradox" is related to the fact that there is no appropriate tool to evaluate all the benefits that accompany the integration of electronic services.

Traditional research methods do not correspond to the modern needs for evaluation the impact of information technology [6]

Studies, as a rule, do not reflect all the benefits which are associated with the introduction of modern technology (Bryjolfsson\&amp; Hitt, 1998).For example, the introduction of information technology may not reduce costs relating to business activity, but it can significantly increase service quality and improve the ways for getting access to services. In addition, within the frames of electronic governance effects research it may be impossible to transform the electronic governance into measurable variables. Thus, it makes difficult to obtain objective results. For the sake of objectivity, it should be noted that it is not justified to associate the "Electronic Government paradox" with the absence of an appropriate research tool. In some cases, the introduced 27-digit service was not used by citizens at all. Therefore, the reasons for failure should not be searched in an inadequate research framework but somewhere else. Electronic governance is a combination of many interrelated factors. Consequently, in the process of studying it is necessary to analyze the overall picture, not only one specific aspect.

An important component of state information and communication technology infrastructure is cyber security, which is one of the most important factors of the introduction of electronic governance as well as ICT.[7]

Governments should think about long-term results, instead of instant profit for successful implementation of electronic governance reform. Reorganization of public space 
must become a part of the reform, in particular, the reduction of the bureaucratic apparatus, at the expense of so-called "back-30 offices" and public servants, as one of the main goals of the introduction of electronic services is to increase the flexibility of the overgrown public sector. $[8$

One of the most outstanding theories about the introduction of modern technologies and society's attitude to innovations is the Hofstede Model, which analyzes the impact of elements of national culture on the process of adopting new technologies by society. The Hofstede system researches five dimensions of national culture, including: power distance how society copes with inequality; individualism / collectivism; group action (masculine / feminine); acceptance of gender issues; focusing on long-term / short-term goals. According to the mentioned criteria, many scientists have tried to determine the influence of cultural elements on the acceptance of new technologies. One of the well-known examples is Grover's study, which sought to determine citizens' attitude to 38new computer technologies in the United States, France, and the Republic of Korea [9].

Among the tools, which are used for measuring society's ability to adapt to innovations, Technology Acceptance Model (TAM) is considered to be the outstanding one (Merchant, 2007) as well as the Unified Theory of Acceptance and Use of Technology (UTAUT).If the TAM system measures the degree of public acceptance of innovation from a business model perspective (Al-adawi, 2005), the UTAUT model focuses on identifying the factors that influence on the introduction / adoption of electronic eservices (Al-awadhi\& Morris, 2008). One of the most well-known interpretations of the TAM tool belongs to Fred Davis, who outlined 4 key determining factors of the approach:

1) Perceived usefulness (PU) - a citizen's attitude to the usefulness of a particular system;

2) Perceived ease of use (PEOU) - a citizen believes that a particular system is safe and easy to use;

3) Behavioral - certain behavior based on the first two variables;

4) Actual system - the last stage of the system, when a citizen makes a decision whether to use the new system or not;

The methodology, used in this study, combines the criteria which enable to Compare different states or state agencies. In particular, it is based on three main axes: online services, information technology infrastructure and human capital in the country. Finally, after analyzing all three aspects, an electronic government development index is established in a particular State.

Taking into consideration that the study combines three different areas, the methods of data collection also differ. For example, data on information and communication technology infrastructure is mainly based on reports of the International Telecommunications Union (ITU).

Along with the development of electronic governance it became necessary to use electronic contracts, electronic signatures and conclude transactions electronically and remotely. This poses new challenges to society and raises many questions about an electronic contract and/or a contract confirmed/signed by facsimile. Therefore, at present, one of the most important issues is to conclude contracts electronically using digital technologies. 
The first international legislative act on an electronic contract is the Model Law on Electronic Commerce adopted by the United Nations Commission on International Trade Law (UNCITRAL) in1996.

Although the Law is of a recommendatory nature, UNCITRAL seeks to create a platform for international recognition of electronic contracts for the parties whose national laws do not provide for such regulation or do not adequately protect the parties. For this purpose, UNCITRAL adopted the Model Law on Electronic Signatures in 2001 to help countries harmonize their legislations and equate an electronic signature with a handwritten one on the basis of a functional-equivalent approach.

There is also Directive 97 / 7EC of the European Parliament and of the Council of 20 May 1997 on the protection of consumers in respect of distance contracts.

In June 2014 within the framework of European Union Association Agreement Georgia made a commitment to harmonize its national legislation with the legislation of the EU. In view of the above, the Law of Georgia on Electronic Documents and Electronic Trust Services was adopted on April 21, 2017. The law defines the concepts of an electronic document and electronic signature, their types and rules for their use. This law replaced the previous Law of Georgia on Electronic Signature and Electronic Document adopted on.

The current Law of Georgia on Electronic Documents and Electronic Trust Services reflects all the innovations which were worked out within the framework of Regulation (EU) No 910/2014 of the European Parliament and of the Council of 23 July 2014 on electronic identification and trust services for electronic transactions in the internal market and repealing Directive 1999/93/EC. In particular, the law provides for such concepts as "qualified electronic signature", "qualified electronic seal", "signature creation data", "signature verification data", "qualified trust service provider", etc. [10].

It is important to note the new content of "written document" itself, which is formed as follows:

a) Electronic document - a set of textual, audible, visual or audio-visual information and/or data stored in an electronic form;

b) Tangible document - a set of information and/or data on paper or in any other tangible form;

It is noteworthy that all copies of an electronic document are originals. An electronic document does not have an electronic copy.

An electronic document and its tangible version have the same legal force if it has been certified and/or verified by an authorized person

The use of an electronic document is permitted in all cases where a tangible document in a written form is required, unless otherwise determined by law.

The same law defines an electronic signature as "a set of electronic data that is attached to or logically linked with an electronic document and is used for signing the electronic document ".It can be a signature if there is an electronic version of the signature on the electronic document that confirms the will of the party.

Along with an electronic signature, the law defines the concept of "electronic seal" as "set of electronic data that is attached to or logically linked with an electronic document and is used for verifying the integrity and origin of the electronic document". It is also interesting 
to note that the legislator distinguishes "electronic signature" from "qualified electronic signature," as well as "electronic seal" from "qualified electronic seal" [11].

It should be noted that a qualified electronic signature is an advanced electronic signature that is created on the basis of a qualified electronic signature certificate. The legislator's approach is similar to a qualified electronic seal. It is noteworthy that the use of a qualified electronic signature and a qualified electronic seal is possible only by means of a special computer program, reader and electronic codes.

An "advanced electronic signature" and "advanced electronic seal "must meet some specific requirements which enable to identify the signatory and the creator of a seal.

It is notable that the law does not directly define the legal force of any electronic signature, since only a "qualified electronic signature has the same legal effect as a handwritten signature". A qualified electronic seal makes it possible to verify the integrity and origin of an electronic document.

If a natural person or a legal entity under private law chooses an electronic form to communicate with administrative bodies and the submitted document requires a signature and/or a seal, it is mandatory to put a qualified electronic signature and/or a qualified electronic seal on the document. This procedure does not apply to cases when the Government of Georgia does not require a signature and/or a seal on the document. An administrative body is obligated to put a qualified electronic signature and/or a qualified electronic seal on an electronic document [12].

The world economy is gradually shifting to electronic forms of communication. Automated enterprises, unmanned transport, freight flows, and logistics are already being created by means of digital technologies. The highly developed world is entering the "Industry 4.0" phase, when the explosion of changes is expected in any sphere of human activity. Electronic transmitters and sensors for sending information are being introduced everywhere. In this regard, it is very important to use the existing digital technologies within the legal framework.

Despite the urgent need, in today's reality most companies do not use a qualified electronic signature and seal. This opportunity is mostly used by companies which interact with the public sector. The most common form is an electronic document with a facsimile or so-called photo signature and exchanging the document by email. A party may also print an electronic document, an authorized person may sign it and, after scanning the document, convert it back into electronic format and send it to the addressee in this form.

While concluding a contract in electronic form, it must be possible to identify a signatory on the basis of a signature and determine the limits of his or her authority. It is also necessary to confirm the authenticity of a transaction and the will of parties.

It is advisable for parties to make an appropriate stipulation in the text of a contract, namely in what form the contract will be signed and exchanged. In this case an electronically signed contract will have legal force. In addition, it is desirable to indicate the corporate email addresses from which contracts were exchanged. It minimizes the problem of authenticity. In the case of such a stipulation, an electronic document and an electronic signature will have the same legal force as a tangible document and a handwritten signature. However, when documents are exchanged in electronic form, it is sufficient to put an electronic signature on one page. 


\section{Electronic signature creation device called a signature pad;}

Public Service Development Agency of Georgia is purchasing a device for taking a sample of a signature. The following models of this device are supplied: natural Sign Pad Mobile, Step over GmbH and Signotec sigma, signotec GmbH. It should be noted that the above-mentioned models (signature pads) are used by a number of state agencies under the Ministry of Justice.

1. natural Sign Pad Mobile, StepOver GmbH is produced by "Step Over International' 'Each signature creation device has a unique Digital Signature Certificate (4096-bit RSA) for creating a digital signature. Signature is performed by a public key which encrypts the signature's biometric data in the device. Data, encrypted in this way, can never be decrypted in an environment which is not properly protected. The tablet offers maximum security to the user and its data can be submitted to the court, and the signature on it is protected from the possibility of change by the user. It is possible to insert an individual text on the screen, interactive buttons and different types of logo and etc.

2. Signotec sigma, signotec GmbH is produced by “Signotec Web store". As for the security features (RSA), its signature pad has superior security mechanisms, which enable to have a complete chain of evidence in case of a dispute. Different techniques are used according to the integration: PDF documents can be signed in the signature pad, not in a less safe personal computer. Biometric signature data are encrypted in the signature device by a public key. While signing RSA, the content of a signed document and the signature are displayed on the screen. Each tablet has a unique RSA Signature Certificate. The RSA certificate is stored inside the tablet. The panel can generate an RSA certificate. Tablet support: RSA PKCS \# 1 v1.5 (with or without the hash OID), PKCS \# 1 v2.1; certificates can be verified by the Root Authority; supporting hash algorithms are: SHA-1, SHA-256 and SHA-512.

\section{Conclusion}

Thus, we can conclude that electronic governance is an instrument for the functioning of digital democracy. Electronic government as a whole is a system which aims to increase efficiency, transparency and productivity of the relationship between central and local government organizations, businesses and citizens.

In spite of the fact that at present most organizations in the private and public sectors in Georgia manage electronic workflow, there is virtually no area that is fully switched to a qualified electronic signature, which has all secure features in comparison with other electronic signatures and it is fully protected from forgery.

The reasons for the above-mentioned circumstance are different. Although the vast majority of the population of Georgia has an electronic ID card, the proper rates of introduction and use of qualified electronic signature in the country are not revealed. This situation is likely to be caused by various factors such as lack of public awareness, some costs associated with purchasing an ID card converter, as well as some knowledge required to download and install a qualified electronic signature program. In addition, there is some inconvenience for citizens because they should have an ID card as well as its converter and codes in case of necessity. It is also necessary to take into consideration the technical aspect, 
namely the Internet, personal computer, laptop or other proper equipment for downloading appropriate computer programs and connecting appropriate devices.

In the process of working on the scientific article, we observed the situation in the public sector in order to find solutions to the problems relating to the introduction and adoption of electronic workflow and electronic signature. On the basis of the analysis of the information, received from both public and private agencies, we collected the necessary data. The received information gives us the grounds to say that most problems, relating to the introduction and development of electronic services, are directly caused by the fact that a qualified electronic signature is not widespread.

Governments should think about specific goals and long-term results in order to implement the electronic governance reform successfully.

\section{References}

1) Law of Georgiaon Electronic Signatures and Electronic Documents, Legislative Herald of Georgia, March 14, 2008; P. 25-28

2) The Forum of European Supervisory Authorities for Electronic Signature (FESA) working Paper on Advanced Electronic Signature, October 12, 2004 ;

3) Report of Personal Data Protection Inspector. Personal data protection in Georgia. Tb.2015. 37 p.

4) Daniel J. Solove., Paul M. Schwartz „Privacy law Fundamentals“, Publisher IAPP. 2017. P. 318.

5) Warren D., Brandeis L. The right to privacy. Harvard Law Review. 15 Dec. 1890. P. 220.

6) Hanewald R.. Issues and approaches in educational contexts;From cyber bulliying to cyber safety. NY.Nova publishers Inc. 2013. P 3.

7) Maher d., Cyber safety and young people : From practice to policy . NY. Novaa science publishers Inc. 2013, P 59.

8) Oblad T., Trejos-Castillo. Cyberaggression: Comparisons of Cyberbullies and Cybervictims throughout the World. From cyber bulliying to cyber safety. NY.Nova publishers Inc. 2013. P 19.

9) Jolia G. Education and employment in a digital environment. Tbilisi.2021, p.20.http://opac.gtu.ge/cgi-bin/koha/opac-detail.pl?biblionumber=50235

10) Law of Georgia on Electronic Documents and Electronic Trust Services.

11) https://matsne.gov.ge/ka/document/view/3654557?publication=1

12) Last checked 16.12.2021

13) Regulation (EU) No 910/2014 of the European Parliament and of the Council of 23 July 2014on electronic identification and trust services for electronic transactions in the internal market and repealing Directive 1999/93/EC

14) https://www.cygnetise.com/blog/5-2020-3-most-common-concernsadoptingesignatures\#::text $=$ While $\% 20 \mathrm{e} \% 2 \mathrm{Dsigning} \% 20 \mathrm{enables} \% 20 \mathrm{business}$, unautho rised\%20signing\%20and\%20non\%2Dcompliance. Last checked 16.12.2021 